\title{
EL PROCESO DE CONSOLIDACIÓN DEL SECTOR FINANCIERO
}

Dra. Beatriz Hertera García*

\author{
RESUMEN
}

\begin{abstract}
El articulo informa el proceso que aplican los bancos internacionales en la concesión de préstamos soberanos; los mecanismos que usan; los factores para el otorgamiento de estos créditos; la captación de los fondos para dirigirnos a estos préstamos soberanos; etc. Presenta también en sus conclusiones un caso práctico con las modalidades de distribución como bancos lideres, rivales y regionales y sus diversos comportamientos de carácter financiero e institucional.
\end{abstract}

\section{INTRODUCCIÓN}

Necesariamente la consolidación del sector financiero conlleva una mayor concentración del mercado y puede traer una mayor o menor eficiencia microeconómica $y$ macroeconómica en relación con las inversiones, la gestión, la producción, las ventas o la innovación tecnológica. Aunque las aglomeraciones también pueden reducir el sano estímulo que aporta a la eficiencia todo mercado en el que reina la libre competencia, asi una mayor concentración del mercado no significa forzosamente que disminuya la competencia o la eficiencia.

En el contexto específico de países como el nuestro, en los análisis de costo-beneficio de las adquisiciones de control habria sobre todo que tener en cuenta consideraciones tales como la alta concentración del mercado, la estrechez de la oferta de recursos naturales y la demanda del mercado, la importancia de la economía de escala y de alcance y la eficiencia relativa de la integración vertical o el aprovechamiento de fuerzas externas a la empresa en las industrias correspondientes, y la competitividad internacional de estas industrias.

\section{PLANTEAMIENTO DEL ESTUDIO}

La entrada en el mercado doméstico de inversiones extranjeras o de productos importados puede ser que inquieten menos los efectos perjudiciales de las adquisiciones competencia porque se supone que hará aumentar ésta, aunque es cierto que la competencia extranjera puede en algunos casos aumentar la

- Profesora Principal de la Facultad de Ciencias Contables y Vicerrectora Administrativa de la UNMSM. 
concentración del mercado si provoca la expulsión de empresas locales de este último. Sin embargo, la competencia extranjera no es un sucedảneo perfecto de la competencia local, especialmente en los mercados de los países en desarrollo, porque intervienen diversas barreras a la entrada en estos mercados y otros factores, tales como la segmentación de los mercados de productos, las políticas discriminatorias de precios de las empresas transnacionales, la falta de interés de los inversores extranjeros o la carencia de divisas para comprar importaciones. La exposición prematura a la competencia extranjera puede además, si diezma las industrias nacientes, conducir a la sustitución de un oligopolio local por un oligopolio extranjero. Es pues indispensable que exista una verdadera libre competencia en los mercados de los países en desarrollo para que la competencia extranjera contribuya plenamente a incrementar la competencia en esos mercados y por ende a consolidar ciertos sectores.

\section{DESCRIPCIÓN DEL TEMA Y NIVEL DE AVANCE}

La concesión de préstamos soberanos, es decir, el otorgamiento de créditos por los bancos a entidades soberanas $u$ otras entidades con aval del gobierno, puede hacerse mediante préstamos colocados directamente por el prestamista individual o mediante consorcios de prestamistas bancarios en que unos pocos organizadores principales (los bancos directores), juntan un paquete de préstamos en que se venden participaciones a otros prestamistas que no entran en contacto directo con el prestatario. Frente a la demanda incesante de créditos bancarios por las entidades soberanas y la buena disposición crediticio de los bancos, el mecanismo de préstamo de consorcio pasó a ser mucho más importante para movilizar el crédito para las entidades soberanas debido al hecho de que se podian organizar grandes volúmenes de crédito mediante operaciones únicas. Los bancos individuales se muestran cada vez más reacios a prestar sumas siempre crecientes mediante préstamos directos y este mecanismo de consorcio les permite participar en paquetes que involucran a muchos bancos a la vez.

El mecanismo de préstamos de consorcio opera de la siguiente manera. Cuando una entidad soberana decide obtener crédito en el mercado internacional de capitales y hacerlo mediante un préstamo de consorcio de bancos transnacionales, lo primero que hacen es seleccionar a los principales bancos organizadores (los bancos directores) de dicho préstamo, fijar el monto deseado y negociar las condiciones principales del préstamo. El banco director suele reunir a un pequeño grupo de grandes bancos que están dispuestos a garantizar el préstamo, es decir, aportan sus propios recursos financieros si el esfuerzo de comercialización para atraer a otros bancos participantes no cubre el monto. Estos bancos directores, una vez que reciben el mandato del prestatario redactan un contrato en que participan una serie de otros bancos. Asi, por ejemplo, la participación de un crédito por 100 millones de dólares puede ser la siguiente: cuatro organizadores aportan 10 millones cada uno, otros 
siete participantes aportan 5 millones cada uno y 10 participantes aportan 2.5 millones cada uno. Los beneficios principales de este mecanismo es permitir que los bancos internacionales más grandes perciban honorarios y comisiones como organizadores de esos créditos y que los bancos más pequeños participen en créditos internacionales de gran volumen sin necesidad de contar con un extenso sistema internacional de ramas y sucursales ni con la capacidad de evaluar la solvencia de los prestatarios (eso lo realizan los bancos directores del préstamo). En el caso del prestatario, permite la movilización de volúmenes de capital internacional que antes se habia considerado imposible obtener.

En general, se suelen citar cuatro factores principales para explicar la buena disposición de los bancos para otorgar créditos a las entidades soberanas. Éstos son la disponibilidad de recursos, un entorno externo favorable, las condiciones familiares de los préstamos y el supuesto buen uso que harán de ellos los prestatarios. Estos factores se amalgaman para culminar en el nuevo acceso al mercado internacional de capitales mediante la intermediación financiera de los bancos.

En el pasado, los principales bancos con acceso a los depósitos en euromoneda (cuando se produjo la expansión del mercado de la euromoneda, debido a que una parte social de las colocaciones internacionales de los exportadores de petróleo eran depósitos bancarios colocados en ese mercado), es decir, los bancos pasaron a ser recicladores fundamentales de los excedentes de esos países, promoviendo en nuevo instrumento de sindicación para la organización de créditos bancarios internacionales lo que facilita el auge crediticio. Los mercados de la euromoneda permiten que los grandes bancos adquieran depósitos de corto plazo no regulados con fines crediticios $y$, según se mencionó, el mecanismo de los consorcios permite que esos mismos bancos dominantes organicen $\mathrm{y}$ administren la participación de los bancos regionales y más pequeños en grandes créditos internacionales, movilizando con ello recursos de participantes alejados del mercado internacional de capitales. Al mismo tiempo muchos clientes tradicionales de los bancos (los gobiernos y las empresas privadas más grandes) reducen su demanda de créditos en euromonedas en la medida en que tiene éxito en efectuar ajustes al impacto del alza de precios. En estos casos se produce una virtual explosión en la existencia de capital de empréstitos a disposición de los bancos grandes.

Cuando el entorno externo es muy favorable para que los bancos transnacionales reciclen recursos financieros excedentarios y las políticas de los países industrializados como los de la Organización de Cooperación y Desarrollo Económico lo fomentaban por varias razones. Significa una solución de sector privado o de mercado a los desequilibrios externos de los paises en desarrollo. Así, estos paises se liberaban de todo compromiso adicional de envergadura para un incremento de la asistencia oficial al desarrollo. Las condiciones de los nuevos créditos de los BT fueron un gran estímulo para la rápida aceleración de la demanda. La tasa de interés real de esos préstamos no es un desincentivo para los bancos intermediarios debido al hecho de que sus ingresos provienen fundamentalmente de una diferencia o margen (spread) sobre la base de interés (a menudo la LIBOR), más comisiones. 


\section{CONCLUSIONES}

Las conclusiones sólo abarcan los préstamos de consorcio colocados en el sector público del país prestatario o garantizados por êste. No comprenden todo el financiamiento externo de los bancos transnacionales, es decir, el sector público y privado. garantizado de largo y corto plazo, vinculado o no con el comercio; lamentablemente dicha tarea escapa al ámbito del proyecto. La información indirecta permitió efectuar ciertas aproximaciones importantes, sobre todo cuando se aborda el tema del riesgo que corren los BT en el sector privado no garantizado, no obstante, las limitaciones de datos condicionan en parte las conclusiones del presente estudio.

Se observó que, según su tamaño y el comportamiento general en la organización de créditos de consorcio durante el auge económico, los principales bancos organizadores de dichos créditos podian dividirse aproximadamente en tres grupos: 1) cinco grandes bancos estadounidenses (Citicorp, Chase Manhatan, Bank America Corp. J.P. Morgan and Co. y Manufacturers Hannover), que dominaban el proceso de los préstamos soberanos de consorcio; 2) diez bancos relativamente más pequeños, sobre todo de origen no estadounidense que competian activamente con el primer grupo en la organización de créditos de consorcio; y 3) otros diez, en su totalidad grandes bancos no estadounidenses que aunque dedicados a la organización de los créditos de consorcio, eran en general menos activos que los primeros dos grupos líderes, los rivales y los seguidores, respectivamente. Sobre la base de la literatura existente se planteó la hipótesis de que un grupo de rivales habia socavado mediante la competencia de precios la posición de los líderes en el mercado de préstamos de consorcio. Las conclusiones demuestran que si bien la hipótesis era correcta, el comportamiento de lo bancos transnacionales es mucho más complejo de lo previsto.

\section{BIBLIOGRAFIA}

1. llet, Issues in Negotiating Loan Agreements with Transnational Banks, Naciones Unidas, Nueva York, 1983.

2. R. de Vries Global Capital Markets Issues and Implications, Georgetowm University, Washington, D.C., 1986.

3. D. Folkerts-Landau, The changing Role of International bank leading in developing Finance, IMF, Washington, D.C. 1984,

4. Herring, R. y A. Santomero, The Corporate Structure of Financial Conglomerate, Journal of Financial Services Research, 1990.

5. International Banking Focus, Annual Global Survey of Regulatory and Market Development in banking, insurance, securities and other financial services, Nueva York, 1992. 